\title{
Inhibition of cellular proliferation by the Wilms tumor suppressor WT1 requires association with the inducible chaperone Hsp70
}

\author{
Shyamala Maheswaran, ${ }^{1}$ Christoph Englert, ${ }^{1,6}$ Gang Zheng, $^{2}$ Sean Bong Lee, ${ }^{1}$ Jenise Wong ${ }^{1}$ \\ D. Paul Harkin, ${ }^{1}$ James Bean, ${ }^{1}$ Robert Ezzel,, ${ }^{3}$ A. Julian Garvin, ${ }^{4}$ Robert T. McCluskey, ${ }^{2}$ \\ James A. DeCaprio, ${ }^{5}$ and Daniel A. Haber ${ }^{1,7}$ \\ ${ }^{1} \mathrm{M}$ assachusetts General Hospital Cancer Center and ${ }^{2}$ Laboratories of Pathology and ${ }^{3}$ Surgical Research, Massachusetts \\ General Hospital (MGH) and Harvard M edical School, Charlestown, Massachusetts 02129 USA; ${ }^{4}$ Department of Pathology, \\ Wake Forest University School of M edicine, Winston-Salem, N orth Carolina 27157 USA; and ${ }^{5}$ Department of Adult \\ Oncology, Dana-Farber Cancer Institute, Boston, M assachusetts 02115 USA
}

The Wilms tumor suppressor WT 1 encodes a zinc finger transcription factor that is expressed in glomerular podocytes during a narrow window in kidney development. By immunoprecipitation and protein microsequencing analysis, we have identified a major cellular protein associated with endogenous WT 1 to be the inducible chaperone Hsp70. WT 1 and Hsp70 are physically associated in embryonic rat kidney cells, in primary Wilms tumor specimens and in cultured cells with inducible expression of WT 1. Colocalization of WT 1 and Hsp70 is evident within podocytes of the developing kidney, and Hsp70 is recruited to the characteristic subnuclear clusters that contain WT1. The amino-terminal transactivation domain of WT 1 is required for binding to Hsp70, and expression of that domain itself is sufficient to induce expression of $\mathrm{Hsp70}$ through the heat shock element (HSE). Substitution of a heterologous Hsp70-binding domain derived from human DNAJ is sufficient to restore the functional properties of a WT 1 protein with an amino-terminal deletion, an effect that is abrogated by a point mutation in DNAJ that reduces binding to Hsp70. These observations indicate that Hsp70 is an important cofactor for the function of WT 1, and suggest a potential role for this chaperone during kidney differentiation.

[Key Words: WT 1; hsp70; p21; Wilms tumor; renal development; cell cycle arrest]

Received October 21, 1997; revised version accepted February 27, 1998.

WT1 encodes a tumor suppressor that is expressed in precursor cells of the kidney glomerulus (for review, see Haber and Housman 1992; Hastie 1994). Its devel opmental role is best demonstrated in WT1-null mice, which show wi despread apoptosis of renal stem cells and failure of renal mesenchyme to respond to normal inductive signals (Kreidberg et al. 1993). In humans, heterozygous germ-line WT1 mutations are associated with genito-urinary malformations and confer genetic predisposition to Wilms tumor, a pediatric cancer originating from renal precursor cells (Huff et al. 1991; Pelletier et al. 1991a,b). WT1 mutations are found infrequently in sporadic Wilms tumors, which typically express high levels of wild-type gene product, consistent with a developmental arrest at an early stage of renal differentiation (Haber et al. 1990; Little et al. 1992; Varanisi et al. 1994). Trans-

\footnotetext{
6Present address: Forschungszentrum, Karlsruhe, Germany. ${ }^{7}$ Corresponding author.

E-MAIL haber@helix.mgh.harvard.edu; FAX (617) 726-5637.
}

fection of wild-type WT1 into a Wilms tumor cell line with an aberrant endogenous transcript results in growth suppression, consistent with its function as a tumor suppressor (Haber et al. 1993). However, the functional properties of WT 1 are complex and dependent on experimental conditions as well as a number of physiological alternative splice variants.

The WT 1 isoform denoted (-KTS) binds to multiple GC and TC-rich promoters through four zinc finger domains, mediating transcriptional repression in promoterreporter assays (for review, see Rauscher III 1993). Inducible expression of this isoform in a WT1-responsive osteosarcoma cell model leads to cell cycle arrest followed by apoptosis, associated respectively with the induction of the cyclin-dependent kinase inhibitor p21 and repression of the epidermal growth factor receptor (EGFR) (Englert et al . 1995a, 1997). When expressed in these cells at levels below those required to inhibit cellular proliferation, WT1(-KTS) inhibits apoptosis triggered by p53 and DNA damage response pathways (Maheswaran et al. 
1995), consistent with the observation of widespread cell death in the devel oping kidneys of WT1-null mice (Kreidberg et al . 1993). The most prevalent WT 1 splicing variant has an insertion of three amino acids disrupting the spacing between zinc fingers 3 and 4 (Haber et al. 1991), resulting in reduced DNA binding activity and diminished ability to inhibit cellular proliferation (Rauscher III et al. 1990; Englert et al. 1995a). Unlike the diffuse nuclear expression pattern observed with WT 1(-KTS), the WT 1(+KTS) isoform is localized to discrete subnuclear clusters (Larsson et al . 1995). Binding to subnuclear clusters, which requires the amino terminus of WT 1, is markedly enhanced in dominant-negative mutants with a disrupted DN A binding domain (Englert et al. 1995b). Although the functional interactions between WT 1 isoforms are unknown, the evolutionary conservation of these splicing variants (Kent et al . 1995), their consistent coexpression in WT 1-expressing cells (Haber et al. 1991), and the presence of WT1-associated subnuclear clusters in cells of the differentiating kidney (M undl os et al . 1993) suggest a physiologi cal ly important relationship.

Heat shock proteins are a highly conserved family of molecular chaperones, with diverse functions, including mediating protein folding and degradation, transport across cellular membranes, and assembly into macromolecular structures (Creighton 1991; Schlesinger 1991; Johnson and Craig 1997; Hartl 1996). Those migrating at 65-70 kD include the constitutive $\mathrm{Hsc70}$, an abundant protein known to bind abnormally folded proteins, including mutant p53 (Pinhasi-Kimhi 1986; Finlay et al. 1988; Hainaut and Milner 1992), and the inducible Hsp70 proteins, which are expressed at low levels physiologically but are rapidly induced following growth of cells at $40^{\circ} \mathrm{C}$ (Lindquist and Craig 1988; Hightower 1991). During growth at a physiological temperature, Hsp70 expression is tightly regulated during cell cycle progression (Milarski and Morimoto 1986) and it is induced by stimuli that induce cellular proliferation, including serum (Wu and Morimoto 1985), expression of c-myc (Kingston et al. 1984), and the viral oncoproteins adenovirus E1A (Kao and Nevins 1983; Wu et al. 1986) and large T from SV 40 and polyoma (Khandjian and Turler 1983). Induction of $\mathrm{Hsp70}$ by viral oncoproteins is associated with disruption of an inhibitory complex containing p53 and CCAAT Binding Factor (CBF), that targets the CCAAT site within the hsp70 promoter (Jones et al. 1987; Lum et al. 1992; A goff et al. 1993). In contrast, both the heat shock response and the cell cycle regulation of $\mathrm{Hsp} 70$ expression are linked to activation of heat shock factor (HSF) family members binding the heat shock element (HSE) within the promoter (for review, see Sorger 1991; Wu 1995). Although less well characterized than its induction by proliferation signals, $\mathrm{Hsp70}$ is also induced in models of hematopoietic differentiation (Sistonen et al. 1992; Garcia-Bermejo et al. 1995; Teshima et al. 1996; Leppa et al. 1997). However, the function of hsp70 in these physiological pathways is unknown.

In searching for endogenous cellular proteins interact- ing with WT1, we observed that WT 1 and Hsp70 are physically associated in cells of the developing kidney, in primary Wilms tumor specimens, and in cultured cells expressing WT 1. Expression of WT 1 induces hsp70 through the HSE regulatory element, and the two proteins products show precise subnuclear colocalization. Of particular importance in defining the functional significance of this protein interaction, deletion of the amino-terminal domain required for binding to $\mathrm{Hsp70}$ abrogates the ability of WT 1 to inhibit cellular proliferation, whereas substitution of a heterologous $\mathrm{Hsp70}$ binding sequence derived from human DNAJ restores its function. By modulating the functional properties of WT 1, Hsp70 may play an important role in normal kidney differentiation and in the functional property of this tumor suppressor.

\section{Results}

Coimmunoprecipitation of Hsp70 with WT1

To gain insight into the functional properties of WT1, we undertook to identify associated cellular proteins. Because WT 1 is normally expressed transiently during glomerular differentiation and is not readily detectable in cultured cells, we established osteosarcoma cell lines with inducible, tetracycline-regulated WT1. Metabolic labeling of these cells, foll owed by immunoprecipitation analysis using antibody against WT 1 revealed a coprecipitating protein migrating around 65 kD (Fig. 1A). Coprecipitation of the $65 \mathrm{kD}$ band was observed by use of antibodies raised against both the amino terminus (WT c8) and the carboxyl terminus (C19) of WT 1, and it was also observed following transfection of HA epitopetagged WT1 into Cos-7 cells, indicating that it did not result from cross reactivity with a specific antibody. WT 1 immunoprecipitation analysis of unlabeled extracts from neonatal rat kidneys, followed by detection of proteins with silver staining was used to confirm coprecipitation of the $65 \mathrm{kD}$ protein with endogenous WT 1 (data not shown). To obtain sufficient material for microsequencing analysis, we isolated extracts from U2OS cells with inducible WT1-delZ, a carboxy-terminal deletion mutant that fails to induce cell death, but has unaltered association with the $65 \mathrm{kD}$ protein. Extracts from $\sim 10^{9}$ cells were immunoprecipitated by use of anti body against WT 1 that had been covalently crossl inked to protein A-Sepharose, followed by preparative gel electrophoresis, immunoblotting, and excision of the $65-\mathrm{kD}$ band. Microsequence analysis of several peptides obtained following proteol ytic digestion, reveal ed the identity of the protein as either Hsp70.1 or Hsp70.2, two members of the inducible subset of heat shock proteins with virtually identical protein sequence (Fig. 1B) (Hunt and Morimoto 1985; Wu et al. 1985; Milner and Campbell 1990; Bonnycastle et al. 1994). To confirm the identification of the WT1-associated protein as Hsp70, WT 1 immunoprecipitates from cells with inducible WT 1 were analyzed by Western bl ot by use of antibody raised against the inducible subset of $\mathrm{Hsp} 70$ proteins (antibody 


\section{B \\ TTP(S)YVAFTDT(E)R}

A

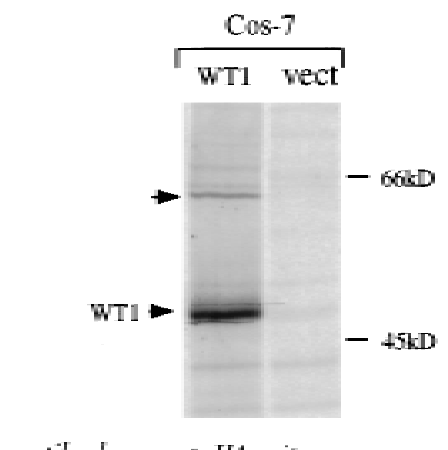

antibady

a-HA epiope

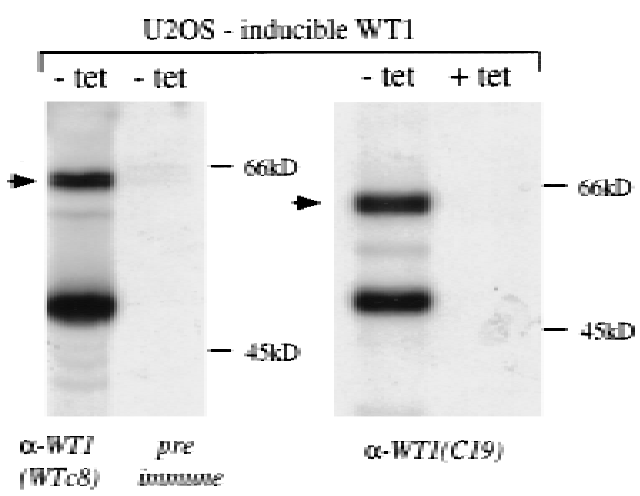

\section{EIAEAYLGYPVTNAVITV(P)AY}

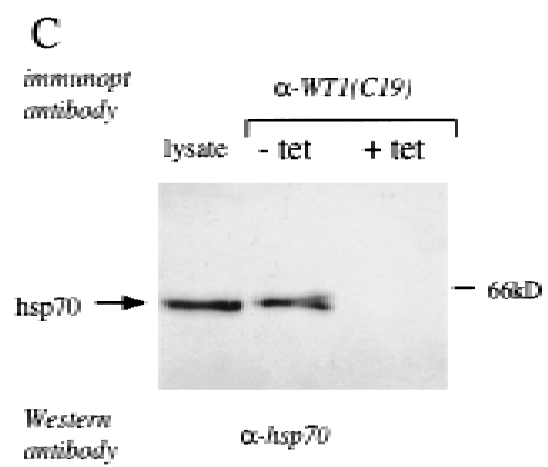

Figure 1. Coimmunoprecipitation of WT 1 and Hsp70. (A) (Left) Immunoprecipitation of metabolically label ed cellular lysates from Cos-7 cells transfected with an HA-epitope tagged WT1 construct or vector, with the 12-CA-5 monoclonal antibody directed against the HA-epitope. (Middle) Immunoprecipitation of label ed lysates from U2OS cells with tetracycline-regulated expression of WT 1. WT 1 expression was induced by withdrawal of tetracycline and extracts were immunoprecipitated with the polyclonal antibody WT C8, directed against the amino terminus of WT1, or its preimmune serum. (Right) U2OS cells were grown in the presence or absence of tetracycline, followed by metabolic labeling and immunoprecipitation with the monocl onal antibody C19, directed against the carboxyl terminus of WT1. The arrow denotes the migration position of the coprecipitated band of $\sim 65 \mathrm{kD}$. (B) Amino acid sequence of two peptides derived from microsequencing of proteolytic products, showing identity with Hsp70.1 and Hsp70.2. Parentheses denote probable, but not definitive residues. (C) hsp70-Western bl ot of anti-WT 1 immunopreci pitates, derived from U $20 S$ cells with inducible WT1 grown in the presence or absence of tetracycline. Cellular lysate (1/10 the amount immunoprecipitated) was analyzed directly to demonstrate the migration position of native $\mathrm{Hsp70.}$

K20; Santa Cruz), demonstrating coprecipitation of these two proteins (Fig. 1C).

Physical association of endogenous WT1 and Hsp70 in rat kidney cells and Wilms tumor specimens

Given the known binding of heat shock family members to poorly folded proteins, we were concerned that the physical association between WT1 and Hsp70 might simply result from its overexpression in cells with an inducible promoter. To determine whether endogenous WT 1 was associated with Hsp70, we first analyzed an immortalized cell line derived from embryonic day 13 rat kidney and known to express native WT1. Immunoprecipitation of proteins from cellular extracts with the carboxy-terminal anti-WT 1 antibody C19, followed by immunoblotting with antibody against $\mathrm{Hsp70}$ demonstrated coprecipitation of these two proteins (Fig. 2A). As a control, Hsp70 was not identified following immunoprecipitation with an irrelevant antibody (against c-Rel). We then analyzed four specimens of sporadic Wilms tumor known to express wild-type WT1. In all four cases, immunoprecipitation-Western analysis, this time with the amino-terminal anti-WT1 antibody WT c8, demonstrated coprecipitation of WT 1 and Hsp70. Therefore, we concluded that the physical association between WT1 and $\mathrm{Hsp70}$ was present in kidney-derived cells, expressing endogenous WT 1 protein.

To address the stoichiometry of the WT1-Hsp70 in- teraction in cells expressing endogenous levels of these proteins, we analyzed metabolically labeled extracts from embryonic rat kidney cells by immunoprecipitation with either anti-WT1 or anti-Hsp70 antibody. Immunoprecipitation with anti-Hsp70 antibody resulted in the coprecipitation of $\sim 25 \%$ of the total cellular WT 1 that was directly immunoprecipitated with anti-WT1 antibody (Fig. 2B). Similarly, $\sim 25 \%$ of the total cellular Hsp70 that was immunoprecipitated with anti-Hsp70 antibody was coprecipitated by use of anti-WT1 antibody. We conclude that, in embryonic kidney cells expressing native WT 1 and Hsp70, a significant fraction of both proteins is present within a physical complex.

\section{Colocalization of WT1 and Hsp70}

The distinct subnuclear localization patterns exhibited by WT 1 made it possible to use confocal microscopy to confirm the association between WT1 and Hsp70 in vivo. Immunofluorescence analysis of $U 2 \mathrm{OS}$ cells with tetracycline-regulated WT 1 constructs demonstrated the absence of detectable baseline expression of either WT 1 or Hsp70 when cells were grown in the presence of tetracycline (Fig. $3 \mathrm{~A})$. Withdrawal of tetracycline and induction of WT1(-KTS) led to the expected diffuse nuclear expression pattern, with sparing of nucleoli: Staining for $\mathrm{Hsp} 70$ demonstrated an increase in the level of Hsp70 expression (see below), sharing the diffuse nuclear distribution of WT1. In contrast, induction of 


\section{A}

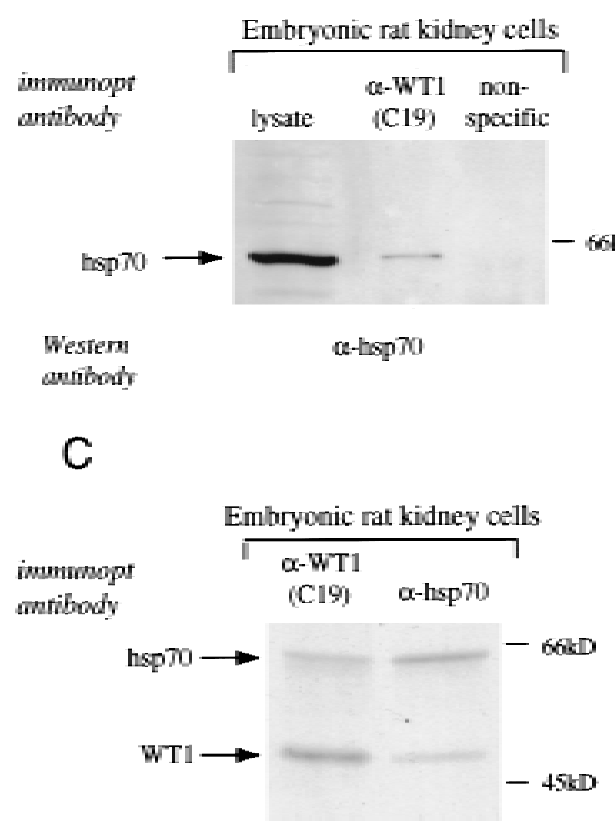

B

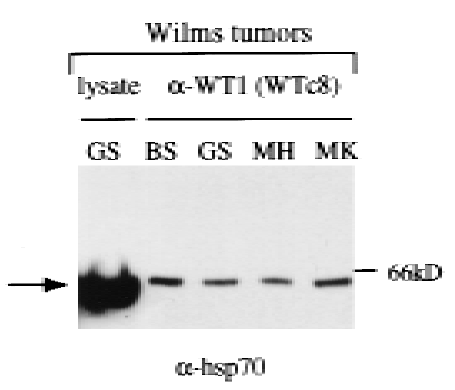

Figure 2. Physical association of endogenous WT1 and Hsp70. (A) Immunoprecipitation-Western analysis of extracts from embryonic rat kidney cells that express endogenous WT1. Equal amounts of cellular lysates were immunoprecipitated with either anti-WT1 antibody C19 or a nonspecific control antibody (against crel), followed by immunoblotting analysis with anti-Hsp70 antibody. Cellular lysate ( $1 / 20$ the amount immunoprecipitated) was analyzed directly to show the migration position of native Hsp70. (B) Immunoprecipitation-Western analysis of lysates from sporadic Wilms tumor specimens. The tumors, denoted by initials, are known to express wild-type WT1. Equal amounts of cellular lysates were immunoprecipitated with anti-WT1 antibody WT c8, followed by immunoblotting with antibody against Hsp70. Cellular lysate from tumor GS (1/20 the amount immunoprecipitated) was analyzed directly by immunoblotting. (C) Immunoprecipitation of radiolabeled Iysates from embryonic rat kidney cells to demonstrate the relative proportion of WT 1 and Hsp70 that are coimmunoprecipitated with each other. Equal amounts of cellular lysates were immunoprecipitated with either anti-WT1 antibody C19 or anti-Hsp70 antibody. The amount of total cellular WT 1 directly immunoprecipitated with C 19 was compared with the amount coimmunoprecipitated with $\mathrm{Hsp70}$ antibody; the amount of total cellular Hsp70 immunoprecipitated directly was compared with the amount coimmunoprecipitated by use of anti-WT 1 antibody C19.

WT1-delZ, which is expressed in a speckled subnuclear distribution, resulted in a similar speckled localization pattern for Hsp70 (Fig. 3A). Staining of these cells with fluorescein-conjugated anti-WT1 antibody and rhodamine-conjugated anti-Hsp70 antibody, followed by analysis by use of confocal imaging, showed precise colocalization of these two proteins within subnuclear clusters (Fig. 3B). Thus, Hsp70 is recruited to the subnuclear compartment containing WT 1 . Inducible expression of EWS-WT1, a tumor-associated chromosomal translocation product in which the amino-terminal domain of the Ewing sarcoma gene (EWS) is fused with the carboxy-terminal zinc finger domain of WT 1 (Ladanyi and Gerald 1994) did not show detectable nuclear Hsp70
A

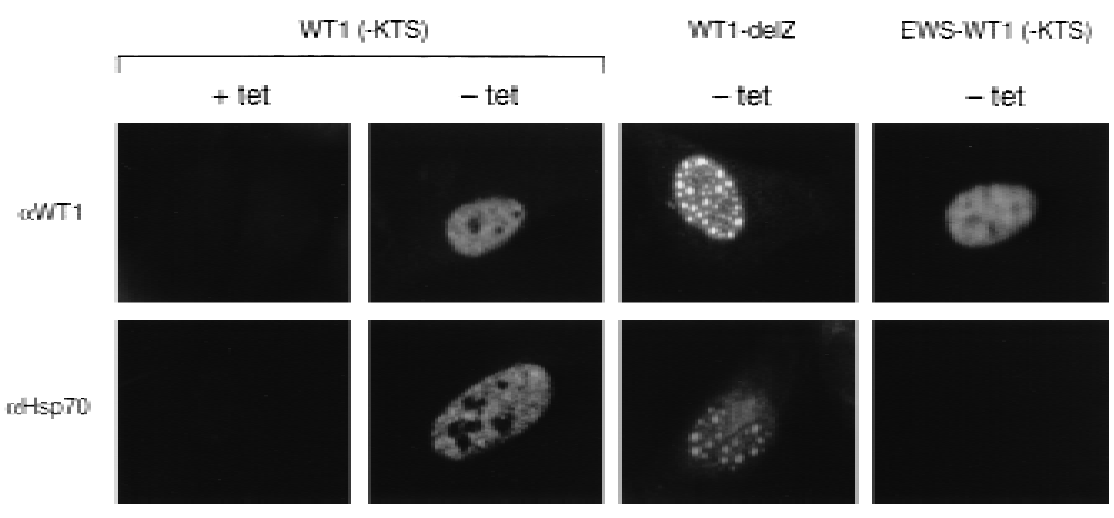

B

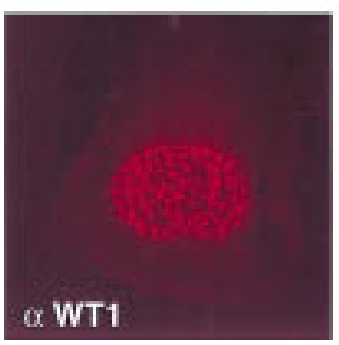

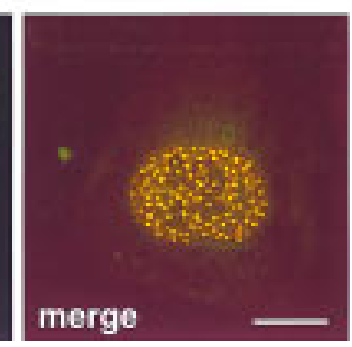

Figure 3. Colocalization of WT1 and Hsp70 in cultured cells. (A) Immunofluorescence analysis of $U 2 \mathrm{OS}$ cells with tetracycline-regulated expression of the wildtype isoform WT1(-KTS), a truncated mutant lacking the carboxy-terminal zinc finger domain (WT1-del Z), and the characteristic chromosomal translocation product identified in Desmoplastic Small Round Cell Tumor (the EWS-WT1(-KTS) chimera, comprised of the amino-terminal domain of the EWS fused to the carboxyterminal zinc finger domain of WT 1). Cells were grown in the presence or absence of tetracycline and stained by use of antibodies against the amino terminus of WT 1 (WT1 (+ and - KTS), the HA epitope tag (EWS-WT1), or against Hsp70. (B) Confocal imaging of U2OS cells with inducible expression of WT1-delZ, following staining with rhodamine-conjugated anti-WT 1 and fluorescein-conjugated anti-H sp70 antibodies. The yellow signal in the merged image identifies precise overlap between red and green signals. Bar, $10 \mu \mathrm{m}$. 
expression (Fig. 3A), indicating that association with $\mathrm{Hsp70}$ is not the consequence of overexpressing zinc finger transcription factors. Induction of Hsp70 expression and its colocal ization with WT 1 specifical ly requires the amino terminus of WT1 (see bel ow), which is present in the WT 1-del Z mutant and lacking in the EWS-WT1 chimera.

\section{Expression of $\mathrm{Hsp} 70$ in the developing glomerulus}

To determine whether the colocalization of WT 1 and $\mathrm{Hsp70}$ was al so evident in cells of the developing kidney that express endogenous WT1, we analyzed histological sections of human fetal kidney. WT1 expression in the kidney is remarkable for its precise devel opmental regulation, with a sharp peak of expression during the differentiation of glomeruli, foll owed by a dramatic decline in the mature kidney (Pritchard-Jones et al. 1990). By immunohistochemistry, WT 1 is detectable in the podocyte layer of the developing glomerulus, in which the presence of both ( - KTS) and (+KTS) al ternative splicing variants leads to a speckled nuclear expression pattern (M undlos et al. 1993). As expected, immunohistochemical analysis of a 13 week human kidney showed speckled nuclear staining restricted to glomerular podocytes (Fig. 4A). Remarkably, staining for $\mathrm{Hsp} 70$ al so revealed high levels of expression restricted to glomerular podocytes of the fetal kidney. Furthermore, in contrast to the cytoplasmic Hsp70 staining pattern in other tissues, immature podocytes showed a speckled nuclear appearance for Hsp70, similar to that observed with WT 1. Rare kidney tubular cells, which do not express WT1, showed Iow levels of cytoplasmic Hsp70 expression. Expression of both WT 1 and Hsp70 was greatly reduced in the adult kidney (data not shown). The striking paral lel pattern of expression of WT 1 and Hsp70 in the embryonic kidney, both in terms of their restriction to a specific cell type and their characteristic subcellular localization, is consistent with a developmentally regulated interaction.

\section{Induction of hsp70 expression by WT 1}

Immunofluorescence analysis suggested that inducible expression of WT1 leads to induction of Hsp70 (Fig. 3A). Quantitation of cellular hsp70 by Western blotting demonstrated low baseline expression that was increased by 5- to 10-fol d following induction of WT1 expression (Fig. $5 A$ ). Northern blot analysis, by use of a gene-specific cDNA probe derived from the 3' untranslated sequence of hsp70.1, showed a fivefold increase in endogenous Hsp70.1 mRN A (Fig. 5B). Consistent with immunofluorescence experiments (Fig. 3), no increase in hsp70 mRNA was observed following inducible expression of the EWS-WT1 chimera, lacking the amino-terminal domain of WT1, or with the tetracycline transactivator alone (Fig. 5B).

The hsp70 promoter has been extensively characterized as a model for transcriptional regulation, leading to the identification of two primary regulatory elements: a CCAAT box between nucleotides 1 and -84 , that is targeted by CBF, and an HSE site between nucleotides -84 and -120 , bound by HSF family members (Rabindran et al. 1991; Sarge et al. 1991; Schuetz et al . 1991). Transient transfection of an hsp70 promoter-CAT construct into U2OS cells showed $\sim 10$-fold transcriptional activation following cotransfection of WT1. Analysis of reporter constructs with progressive deletions of the hsp70 promoter identified the WT1-responsive element between nucleotides -84 and -120 , containing the HSE site and excluding the CCAAT box (Fig. 5B). Requirement for the HSE site was confirmed by use of a minimal reporter construct containing multimeric HSE sites, which showed 85-fold transcriptional activation following cotransfection of WT1 (Fig. 5B). Transcriptional activation a WT1

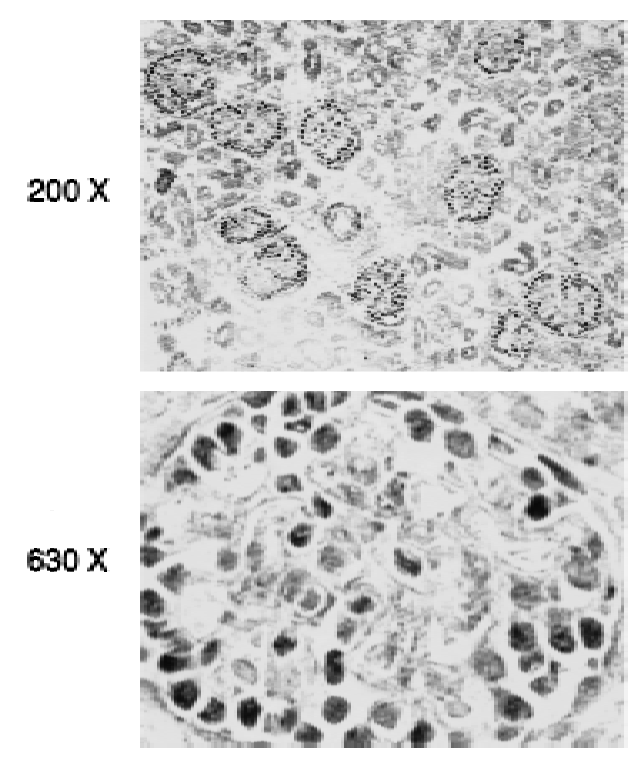

$\alpha \mathrm{Hsp} 70$

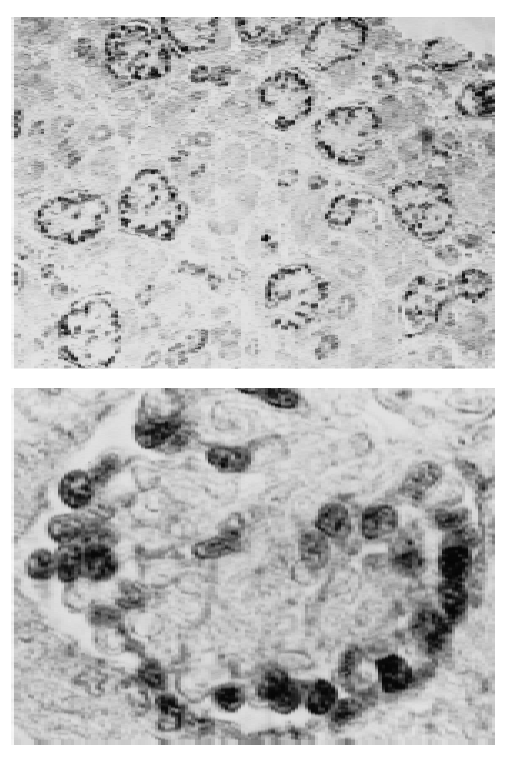

Figure 4. Colocalization of WT1 and Hsp70 in devel oping gl omerular podocytes. Immunohistochemical analysis of sections from a 13-week human kidney, by use of antibodies against WT1 and Hsp70. Low power (200x) reveals devel oping gl omeruli, in which podocytes are seen as a ring of peripheral cells that stain intensely for both WT 1 and Hsp70. The mesangial cells, renal tubular cells, and stroma are negative. At higher power (630X), staining for both WT 1 and Hsp70 is seen to be restricted to the nuclei of podocytes, and exhibit a speckled pattern. 
A

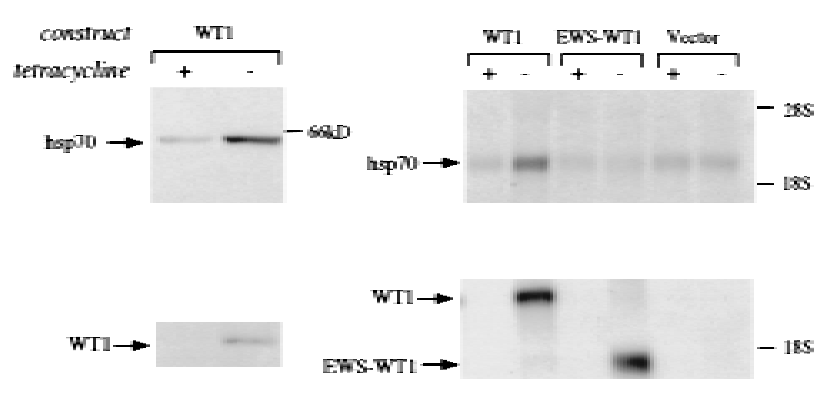

GAPDH $=-10=0$
C

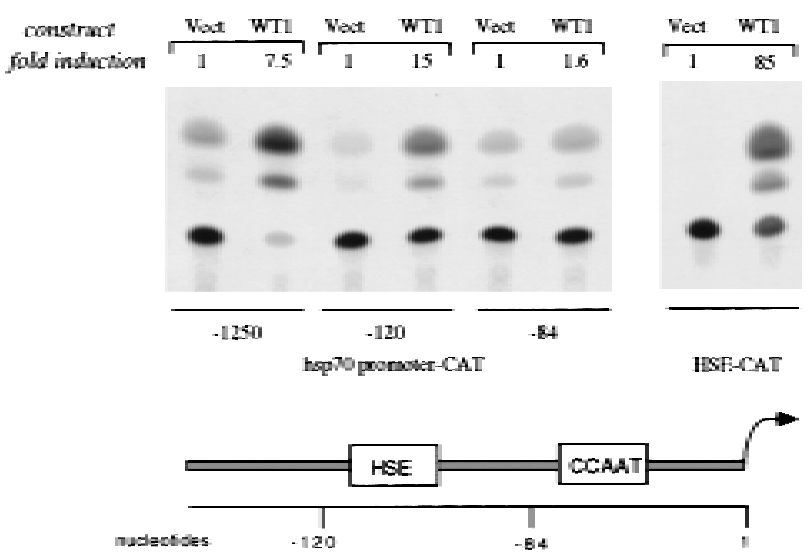

Figure 5. Transcriptional activation of hsp70 by WT 1. (A) Induction of Hsp70 protein following expression of WT1. U2OS cells with inducible expression of WT1 were grown in the presence or absence $(24 \mathrm{hr})$ of tetracycline, and equal amounts of cellular lysates were analyzed by immunoblotting with antibody against Hsp70. Induction of WT 1 is shown at bottom. (B) Induction of hsp70.1 mRN A by WT1. N orthern blot analysis of U2OS cells with inducible WT1, EWS-WT1, or empty vector, following growth in the presence or absence ( $24 \mathrm{hr}$ ) of tetracycline. A gene-specific probe was derived from the 3' untranslated region of human hsp70.1. (Middle) Reprobing of the bl ot with a WT1 cDN A to confirm inducible expression of WT1 and the EWS-WT1 chimera; (bottom) a GAPDH Ioading control. (C) Transcriptional activation of the hsp70 promoter by WT1. U2OS cells were transfected with CMV-driven WT1(-KTS) or empty vector, al ong with reporter constructs, followed by determination of CAT activity. The respective fragments of the hsp70 promoter reporter are shown (bottom), including the primary HSE and CCAAT regulatory elements. The HSE-CAT reporter contains multimerized HSE sites. The fold induction of CAT activity was determined by scintillation counting.

of hsp70 by WT1 was observed following transfection of wild-type WT1 as well as the carboxy-terminal deletion mutant WT1-delZ, demonstrating that this effect was independent of its DNA binding activity (data not shown). Gel retardation assays by use of the HSE sequence also showed no evidence of direct binding by WT 1 (data not shown). These observati ons are consistent with current models of HSE-dependent hsp70 induction (A bravaya et al. 1992; Mosser et al. 1993; Cotto et al. 1996), suggesting that binding of the WT 1 amino-terminal domain to $\mathrm{Hsp70}$ induces release of HSF from its complex with Hsp70, resulting in HSF-mediated induction of hsp70 expression.

Substitution of a heterologous $\mathrm{Hsp70}$ binding domain from DNAJ for the amino terminus of WT1

To determine the functional significance of the WT1Hsp70 complex, we sought to compare the properties of WT 1 in the presence or absence of this protein interaction. Because expression of Hsp70 is ubiquitous, and WT 1 itsel $\mathrm{f}$ induces $\mathrm{Hsp70}$ expression, we were unable to choose a cell type lacking this protein association. Therefore, we chose to identify the minimal WT 1 domain required for association with $\mathrm{Hsp} 70$, determine whether it is required for WT 1 function and then test whether it can be replaced with a heterologous Hsp70binding domain derived from the known $\mathrm{Hsp70}$ cofactor, DN AJ (Langer et al. 1992; Silver and Way 1993; Liberek et al. 1995). We determined previously that the amino terminus of WT1, which is retained in the WT1-delZ mutant, was required for interaction with Hsp70, whereas the zinc finger domain, present in the EWSWT 1 fusion protein, was not invol ved in this interaction. To refine the domain of interaction, we transiently transfected a panel of truncated, HA-epitope tagged WT1 constructs into Cos-7 cells, followed by metabolic labeling and immunoprecipitation analysis. These experiments indicated that the extreme amino terminus of WT 1 (amino acids 6-180) was required for coimmunoprecipitation of Hsp70 (Fig. 6A). Therefore, we used WT 1( $(\Delta 6-180)$ to generate chimeric constructs, in which the deleted extreme amino terminus of WT1 was replaced by the J domain of HSJ 1 , a human DN AJ homolog (Cheetham et al. 1992). Two chimerae were tested, one encoding the wild-typeJ domain (DNAJ-WT1) and one in which an $\mathrm{H}$ to $\mathrm{Q}$ point mutation in the conserved HPDK motif (Campbell et al. 1997; Stubdal et al. 1997) abrogates Hsp70 binding (H42Q-DNAJ-WT1). As predicted, transfection of constructs encoding DNAJ-WT1 into Cos-7 cells followed by immunoprecipitation with antibody to the carboxyl terminus of WT1 resulted in coprecipitation of $\mathrm{Hsp70}$, which was greatly reduced following transfection of H42Q-DNAJ-WT1 (Fig. 6B) As a control for the DNA binding properties of DNAJ-WT1, we also generated a chimeric construct with a disruption of the WT 1 zinc finger domain, DNAJ-WT1-delZ.

WT1-mediated growth inhibition requires binding to $\mathrm{Hsp70}$

Although the precise functional properties of WT1 re main uncertain, its ability to inhibit cellular proliferation appears most consistent with its characteristic as a 
A

Figure 6. Identification of amino-terminal WT 1 domain required for association with Hsp70. (A) Schematic representation of WT1 deletion constructs. The chimeric constructs DNAJ-WT1 encodes the 78 amino acid J domain of human DNAJ (HSJ1). H42Q-DNAJ-WT 1 contains a substitution of gl utamine for histidine within the critical HPD residues required for association with Hsp70 (Wall et al. 1994; Tsai and Douglas 1996). (B) Coimmunoprecipitation of Hsp70 with truncated WT1 proteins. Cos-7 cells were transfected with CMV-driven constructs, followed by immunoprecipitation of radiolabeled lysates with antibody $12-\mathrm{CA}-5$ against the HA epitope. Comparable expression of the WT1 constructs is demonstrated, along with coimmunopreci pitation of $\mathrm{Hsp} 70$ with all WT 1 del etion constructs except $\Delta 6$ 180. (C) Coimmunoprecipitation of $\mathrm{Hsp70}$ with DNAJ-WT1, but not H42Q-DNAJWT1. Cos-7 cells were transfected with CMV driven constructs encoding wild-type WT1 or the WT1-DNAJ chimerae, followed by coimmunoprecipitation with antibody 12-CA-5.

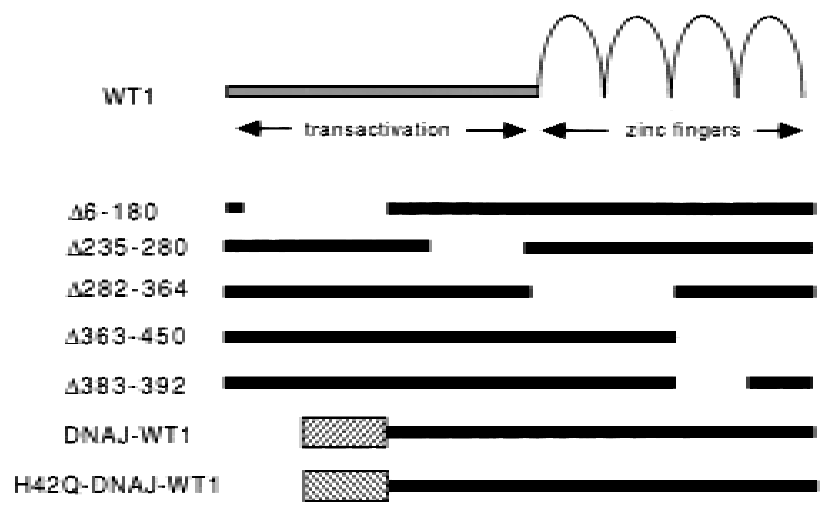

B

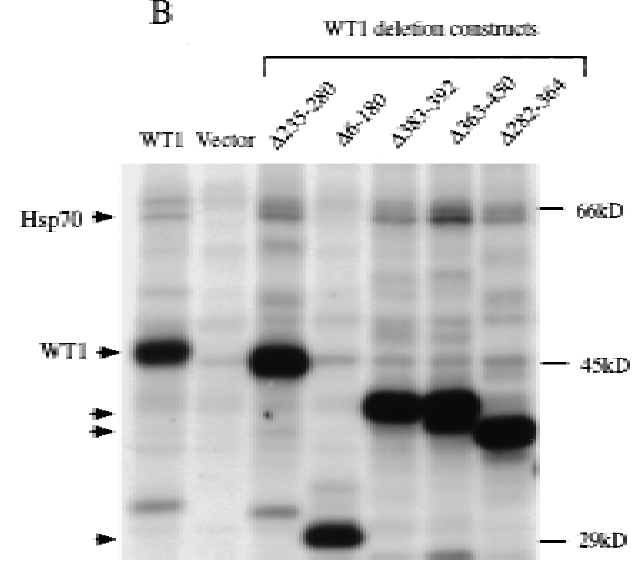

C

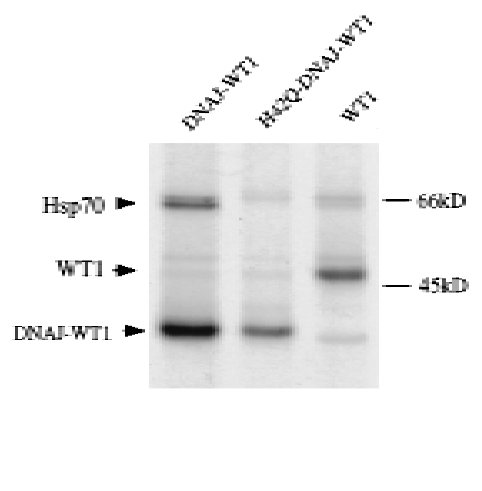

tumor suppressor gene. We have shown previously that WT1 inhibits colony formation in two osteosarcoma cell lines, U2OS and Saos-2. To test the functional consequences of the WT1-Hsp70 interaction, we transfected these cells with constructs encoding WT1, WT1 ( 46 -180), DNAJ-WT1, H42Q-DNAJ-WT1, and DNAJWT1-delZ, al ong with a hygromycin-resi stance pl asmid. As predicted, WT1 suppressed col ony formation in both U 20 S and Saos-2 cells, an effect that was lost following deletion of the amino-terminal domain WT1(46-180). Remarkably, the DNAJ-WT 1 chimera was able to inhibit colony formation to the same extent as wild-type WT1, whereas H42Q-DNAJ-WT1 was inactive (Fig. 7A). DNAJ-WT1-delZ had no effect on colony formation, indicating that this effect required DNA binding by the chimeric protein and was not simply the result of directing nuclear expression of a wild-type DNAJ domain. Similarly, fusion of DNAJ to another nuclear protein, SV 40 T antigen, does not by itself inhibit cellular proliferation (Campbell et al. 1997; Stubdal et al. 1997). Thus, the addition of a heterol ogous Hsp70-binding domain to an amino-termi nal-del eted WT 1 construct was sufficient to restore its ability to inhibit cellular proliferation, suggesting that interaction with $\mathrm{Hsp70}$ is required for growth inhibition by WT1.

To examine the mechanism underlying the inhibition of colony formation by DNAJ-WT1, we first tested its transactivational activity using transient transfection assays. WT 1(-KTS) has been shown to bind to multiple GC- and TC-rich motifs mediating transcriptional repression, although the specificity of this effect has been questioned. As expected, we found that two prototype WT1-responsive promoters, the GC-rich Early Growth Response (EGR 1) promoter (Rauscher et al . 1990) and the TC-rich EGFR promoter (Englert et al. 1995a) were effectively repressed following cotransfection of full length WT1. However, these reporters were also repressed by the amino-terminal deleted construct WT1 $146-180$, which is inactive in mediating growth suppression, as well as by both DNAJ-WT1 and H42QDNAJ-WT1 (Fig. 7B). Hence, we did not observe a correlation between transcriptional repression of these re porter constructs in transient transfection assays and the ability of WT1 variants to inhibit cellular proliferation.

Inducible expression of WT1(-KTS) in Saos-2 cells is also associated with induction of the cyclin dependent kinase inhibitor p21 and $\mathrm{G}_{1}$-phase cell cycle arrest (Englert et al. 1997). To test whether this functional property of WT1 was more closely correlated with their ability to inhibit cellular proliferation, Saos-2 cells were transiently transfected with constructs encoding the variants of WT1 and DNAJ-WT1, along with a plasmid encoding the cell surface marker CD20. Analysis of 
A

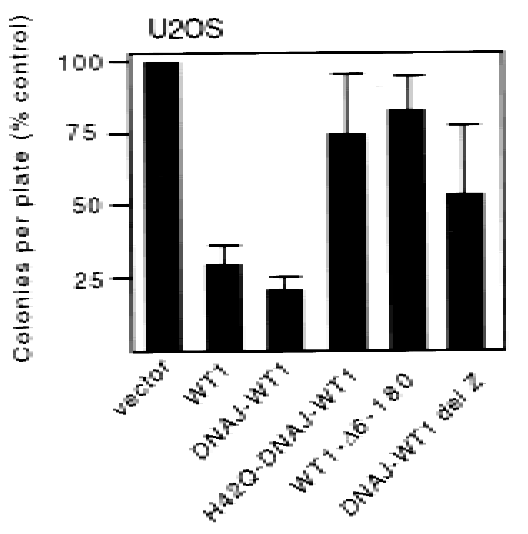

C

\begin{tabular}{lccc} 
Construct & \multicolumn{3}{c}{ Cell Fraction (r) } \\
& G1 & S & G2/M \\
\hline Vector & 51 & 26 & 23 \\
WT1 & 63 & 7 & 30 \\
DNAJ-WTI & 65 & 12 & 23 \\
H42Q-DNAI-WT1 & 56 & 26 & 18
\end{tabular}

B

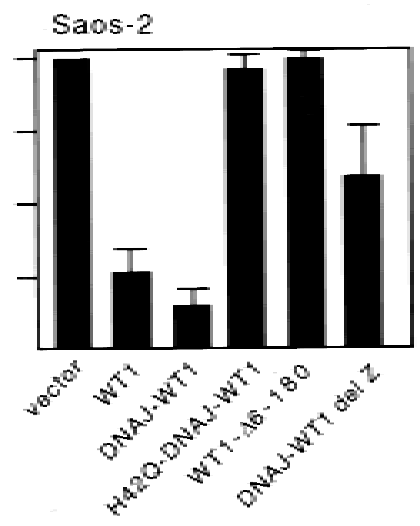

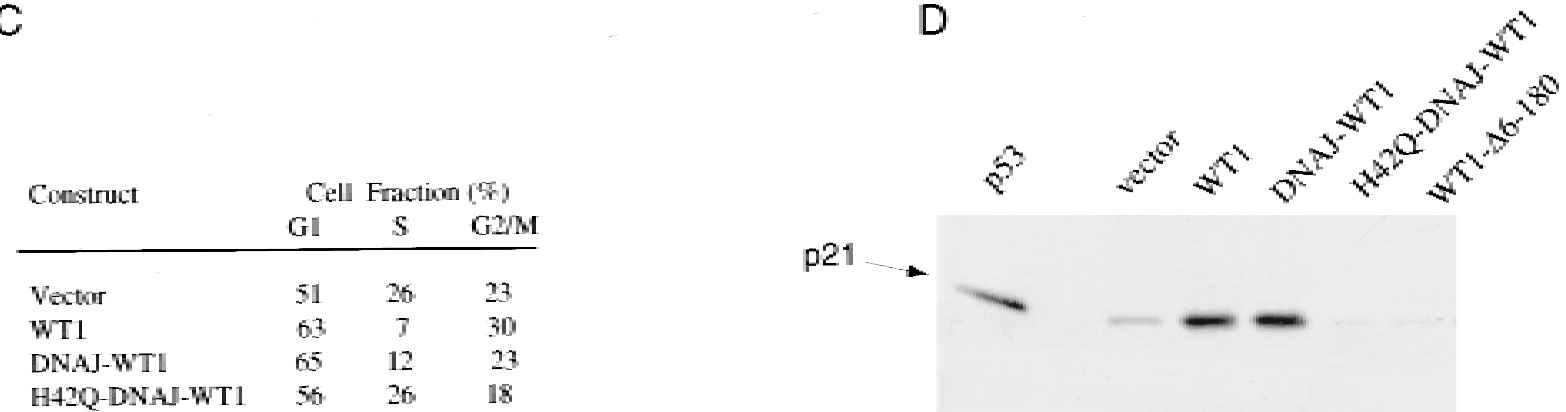

Figure 7. Inhibition of cellular proliferation by WT 1 requires association with $\mathrm{Hsp70}$. (A) Inhibition of col ony formation in $\mathrm{U} 2 \mathrm{OS}$ and Saos-2 cells following transfection of wild-type WT1, the amino-terminal truncation WT1- $\Delta 6-180$, DNAJ-WT1, H42Q-DNAJ-WT1 (encoding a point mutation within the DNAJ domain), and DNAJ-WT1-delZ (encoding a truncation of the WT1 DNA binding domain). All WT1 constructs (except DNAJ-WT1-delZ) encoded the (-KTS) splicing variant, with an uninterrupted DNA binding domain, which has been linked to inhibition of cellular proliferation in these osteosarcoma cells. Cells were cotransfected with a construct encoding puromycin resistance and drug resistant colonies were counted after 14 days (U2OS) or 21 days (Saos-2) in culture. Standard deviations are given. (B) Absence of correlation between transcriptional repression or promoter-reporter constructs and inhibition of colony formation by WT1 variants. U2OS cells were transfected with WT1 and DNAJ-WT 1 constructs, al ong with either the GC-rich EGR1-CAT or the TC-rich EGFR-CAT promoter reporters. Representative experiments are shown, with transcriptional repression quantitated by scintillation counting. (C) $\mathrm{G}_{1}$ phase cell cycle arrest induced by wild-type WT1 and DNAJ-WT1. Saos-2 cells were transiently transfected with WT1 and DNAJ-WT1 constructs, al ong with a construct encoding the cell surface marker CD20. CD20-expressing transfectants were identified by FACS analysis, and their cell cycle distribution was determined by staining with propidium iodide. A representative experiment is shown. (D) Induction of p21 by wild-type WT1 and DNAJ-WT1. Saos-2 cells were transiently transfected with constructs encoding WT1 and DNAJ-WT1 variants. Cellular extracts were isolated $24 \mathrm{hr}$ after transfection, and equal amounts of lysates were analyzed by immunoblotting by use of antibody against p21. Saos-2 cells have a deletion of endogenous p53 and express low levels of endogenous p21; their high transfection efficiency makes it possible to anal yze the induction of the native p21 gene following transient transfection of expression constructs. As a control, induction of p21 is shown following transient transfection of CMV-driven p53 $(1 \mu \mathrm{g})$.

CD20-positive transfectants by FACS for DN A content demonstrated a $10 \%-15 \%$ increase in $G_{1}$ phase following cotransfection with WT1, but not with the truncated WT1- $46-180$. Cells cotransfected with DNAJ-WT1 al so showed a $10 \%-15 \%$ increased $G_{1}$ phase fraction, which was not observed following cotransfection with $\mathrm{H} 42 \mathrm{Q}-$ DNAJ-WT1. Because $\mathrm{G}_{1}$ arrest mediated by WT1 is correlated with induction of p21, we analyzed endogenous p21 levels by immunoblotting, following transfection of WT1 variants into Saos-2 cel Is. Transient transfection is highly efficient in these cells, which have a deletion of p53 and low levels of native p21 expression, making it possible to determine the effect of transfected constructs on endogenous p21 levels. Transfection of WT1 induced a 5- to 10-fold increase in endogenous p21 expression, whereas WT1- $\Delta 6-180$ had no effect. Transfection of DNAJ-WT1 induced an increase in p21 levels comparable with wild-type WT1, but H42Q-DNAJ-WT1 was inactive. Thus, recruitment of Hsp70 to WT1 appears to be requi red for its ability to induce expression of p21 and mediate $\mathrm{G}_{1}$ phase cell cycle arrest, functional properties that are well correlated with the ability of WT1 variants to inhibit cellular proliferation in these cells. 


\section{Discussion}

By coimmunoprecipitation and protein microsequencing anal ysis, we have identified a major cellular protein partner of WT 1 as Hsp70. A number of observations indicate that this protein interaction is physiologically significant: (1) Coimmunoprecipitation of WT 1 and Hsp70 is observed in kidney-derived cells expressing endogenous WT 1, namely embryonic rat kidney cells and primary Wilms tumor specimens, (2) precise subnuclear colocalization of WT 1 and Hsp70 is evident in cultured cells and a striking coexpression pattern is present in glomerular podocytes of the devel oping kidney, (3) WT 1 itself is a potent inducer of $\mathrm{Hsp} 70$ expression, an effect that is mediated through the HSE site of the hsp70 promoter and, hence, may involve the HSF family of transcription factors, and (4) functional studies demonstrate that the extreme amino terminus of WT1, which binds Hsp70 and is required for growth inhibition by WT 1 , can be replaced with a heterologous Hsp70-binding domain derived from a human DNAJ homolog. The reconstituted Hsp70-binding chimeric WT 1 protein has restored ability to inhibit colony formation, induce p21 and mediate $\mathrm{G}_{1}$ phase cell cycle arrest, whereas a chimera with a point mutation disrupting the $\mathrm{Hsp70}$-binding domain is inactive. These observations suggest that binding to Hsp70 is important to the function of WT1 as an inhibitor of cellular proliferation.

Binding of denatured or misfolded cellular proteins to members of the heat shock family is a well known phenomenon, which complicates attempts to distinguish specific physiological pathways in which these chaperones may play an integral part. Analysis of cells with endogenous WT 1 ensures that the association between this protein and $\mathrm{Hsp70}$ is not the result of aberrant overexpression associated with tetracycline-regulated promoters. In embryonic rat kidney cells that express physiologically relevant levels of WT1, $25 \%$ of the cellular WT 1 is associated with $\mathrm{Hsp} 70$ and a similar proportion of cellular Hsp70 is bound to WT1, indicating that an important fraction of these cellular proteins are associated with each other. Similarly, the mapping of this interaction to the extreme amino-terminal domain of WT 1 indicates that $\mathrm{H}$ sp70 recognizes a specific epitope within the transactivation domain. Like a number of other transcription factors (Mitchell and Tijan 1989), the extreme amino terminus of WT1 contains long stretches of prolines, which suggests that Hsp70 binding may allow proper folding of this rigid domain. It is of interest that the amino-terminal domain of WT 1 is poorly soluble when overproduced in bateria and in insect cells, pointing to the need for correct molecular folding. However, binding of Hsp70 is unlikely to simply mediate stabilization of WT1 protein in vivo, because pulsed chase anal ysis did not demonstrate different turnover for WT 1 variants capable of binding Hsp70 (wild-type WT1, DNAJ-WT 1), compared with a protein lacking this interaction domain (H42Q-DN AJ-WT 1) (data not shown). By analogy with its presumed function in other model systems (Creighton 1991; Schlesinger 1991; Hartl 1996;
Johnson and Craig 1997), binding to Hsp70 may therefore ensure correct folding of the amino terminus of WT 1 , enhancing its functional properties and its potential interactions with other proteins (see below).

Expression of the WT 1 amino-terminal domain is itself sufficient to induce expression of hsp70 through the HSE site. This observation distinguishes the effect of WT 1 from that noted for p53, which targets the CCAAT box in the hsp70 promoter through an interaction with CBF (A goff et al. 1993), and it implicates members of the HSF family in WT1-mediated induction of Hsp70. The heat shock response is thought to involve the trimerization and phosphorylation of HSF1, which binds the HSE within the hsp70 promoter (A bravaya et al. 1992; M osser et al. 1993; Cotto et al. 1996). Recently, a second family member, HSF2, has been implicated in the induction of Hsp70 during hematopoietic differentiation (Sistonen et al. 1992; Leppa et al. 1997), and a chicken homolog, HSF3, appears to bind directly to the product of c-myb and mediate cell cycle regulation of Hsp70 expression (Kanei-Ishii et al . 1997). Although we observed increased binding to the HSE element following induction of WT1, we were unable to distinguish between the known family members HSF1 and HSF2 using supershift analysis (data not shown). We did not observe the characteristic phosphorylation of HSF1 following induction of WT1, suggesting that WT1-associated transactivation of hsp70 may be mediated through other members of the HSF family. DN A binding by WT 1 itself is not required for the induction of Hsp70, consistent with the model of HSF-regulated expression of $\mathrm{Hsp70}$, which suggests that binding of $\mathrm{Hsp} 70$ to its target protein leads to its release of free transcri ptional ly active HSF (A bravaya et al. 1992; Mosser et al. 1993; Cotto et al. 1996).

The potent induction of Hsp70 by WT 1 and the physical association between these two proteins suggests a role for Hsp70 in a cellular differentiation pathway. This is consistent with its apparent contribution to steroid hormone response pathways and hematopoietic differentiation. Both Hsp70 and Hsp90 are components of the steroid hormone receptor complex: Hsp90 appears to facillitate binding of the estrogen receptor to its ligand, whereas $\mathrm{H}$ sp70 enhances ligand-independent DN A binding acti vity (Schowal ter et al. 1991; Smith and T oft 1993; Landel et al. 1994). In this context, high levels of Hsp70 expression are noted in the ovary during the natural regression of the corpus luteum, a relative estrogen withdrawal state that follows ovulation (Khanna et al. 1995). Dramatic induction of $\mathrm{Hsp70}$ expression is al so evident during hematopoi etic differentiation induced by sodium butyrate, hemin, or macrophage-col ony stimulating factor (M-CSF) (Sistonen et al. 1992; Garcia-Bermejo et al. 1995; Teshima et al. 1996; Leppa et al. 1997). Whereas induction of HSF2 during hematopoietic differentiation has been reported, the underlying mechanism and the consequences of increased Hsp70 expression are unknown. WT1 is remarkable for its highly restricted expression pattern during glomerular differentiation in the developing kidney (Pritchard-Jones et al. 1990). The coimmunoprecipitation of WT1 and Hsp70 from embry- 
onic rat kidney cells and their striking colocalization within the differentiating kidney therefore points to a developmentally regulated interaction. Although they provide dramatic evidence supporting in vivo colocal ization, the functional properties of WT1-associated subnuclear clusters are unknown. Colocalization of WT 1 alternative splicing variants with snRNPs has led to a postulated role in pre-mRNA splicing (Larsson et al. 1995), whereas the enhanced speckled distribution of proteins encoded by dominant negative WT1 mutants suggests that these structure might be involved in the sequestration of wild-type proein (Engl ert et al. 1995b). It is of interest to note that the induction of $\mathrm{Hsp70}$ by c-M yc or V-M yc is also associated with colocal ization of these proteins within subnucl ear clusters, an effect that is not observed with the closely related protein N-M yc (Koskinen et al. 1991). Further understanding of the identity of these subnuclear structures will be required to determine whether the recruitment of $\mathrm{Hsp} 70$ contributes to their functional properties.

In contrast to the WT1(+KTS) isoform that is associated with subnuclear clusters and whose functional properties are uncertain, the WT 1(-KTS) variant is expressed diffusely in the nucleus and appears to mediate transactivation and inhibit cellular proliferation. Characterizing the contribution of $\mathrm{Hsp} 70$ to these functional properties thus provides insight into the consequences of this protein interaction, as well as into the critical properties of WT 1 itself. Because Hsp70 is ubi quitous and its expression is induced by WT1 itself, we addressed this question by constructing chimeric proteins, in which the amino-terminal WT1 domain required for association with $\mathrm{Hsp70}$ is replaced with a heterologous J domain derived from the known Hsp70 cofactor DN AJ (Langer et al. 1992; Silver and Way 1993; Liberek et al. 1995). The use of such chimeric DNAJ-WT1 constructs, including either the wild-type J domain or a point mutant (H42Q) disrupting its interaction with $\mathrm{H}$ sp70, has been used effectively to dissect the contribution of heat shock binding to the functional properties of SV40 T antigen (Campbell et al. 1997; Stubdal et al. 1997). Our observations indi cate that the extreme amino terminus of WT 1 is required for the inhibition by WT1 of col ony formation in U2OS and Saos-2 cells, a correlate of its function as a tumor suppressor (Englert et al. 1995a). The fact that a heterologous $\mathrm{Hsp70-binding} \mathrm{domain} \mathrm{can} \mathrm{restore} \mathrm{func-}$ tion to an amino-terminal truncated WT1 construct, whereas the $\mathrm{H} 42 \mathrm{Q}$ mutant is inactive, provides strong evidence that $\mathrm{Hsp70}$ binding is important to the inhibition of cellular proliferation by WT1.

Contrary to expectations, the ability of WT1 and DNAJ-WT1 variants to inhibit cellular proliferation was not linked to their activity in repressing transcription from prototype WT1-responsive promoter-reporter constructs. Both DNAJ-WT1 and H42Q-DNAJ-WT1, as well as an amino-terminal deleted WT 1 construct, demonstrated comparable transcriptional repression, by use of both GC-rich and TC-rich target sequences. Transcriptional repression of such reporters by WT1 has been shown to be modulated by promoter and cellular con- text, and even by the choice of expression vector (Maheswaran et al. 1993; Wang et al. 1993; Reddy et al. 1995), raising concern about its physiological significance (Reddy and Licht 1996). In contrast, a distinct functional property of WT1, its ability to induce a $G_{1}$ phase arrest, associated with induction of the endogenous p21 gene (Kudoh et al. 1995; Englert et al. 1997), appears to be well correl ated with its growth suppressive properties. Cell cycle arrest and induction of native p21 were observed following transfection of both wild-type WT1(-KTS) and DNAJ-WT1, but not mutant H42QDNAJ-WT 1 and an amino-terminal WT 1 truncation mutant. These observations, therefore, provide a framework for assessing potential physiological properties of WT1 and they suggest that $\mathrm{Hsp70}$ is an important cofactor in the function of this tumor suppressor.

\section{Materials and methods}

Cell culture and expression constructs

U2OS and Saos-2 osteosarcoma cells with tetracycline-regulated expression of WT1 variants have been described previously (Englert et al. 1995a; M aheswaran et al. 1995). In these cells, withdrawal of tetracycline results in induction of WT1 expression. Rat kidney cells, isolated from day 13 embryos and immortalized with polyoma middle $T$ antigen were kindly provided by D. Herzlinger (Cornell Medical School, New York, NY). Sporadic Wilms tumor specimens expressing wild-type WT1 have been described el sewhere (Haber et al. 1990). CMVdriven expression constructs (pcDN A 3-1; Invitrogen), encoding wild-type splicing variants of WT1 and internal in-frame deletions have been described previously (Maheswaran et al. 1995). Plasmids containing the J domain from the human DNAJ homolog HSJ 1 (Cheetham et al. 1992) were derived from SV40 T antigen chimerae (Campbell et al. 1997; Stubdal et al. 1997). The H to Q mutation ( $\mathrm{H} 42 \mathrm{Q}$ ) within the conserved HPDK motif abrogates binding to $\mathrm{Hsp} 70$. The mutation is at residue 42 in the SV40 T antigen chimera, corresponding to residue 31 in the native HSJ 1 sequence. Constructs in which the amino-terminal domain of WT 1 (amino acids 6-186) is replaced by the 78 amino acid J domain derived from human HSJ 1 were generated by PCR amplification, with an $\mathrm{N}$ col restriction site within the WT1 CDNA. The DNAJ-WT1-delZ chimeric construct, lacking the zinc finger domain of WT 1, was generated by truncating DNAJWT1 with the Rsrll restriction site within WT1. Transient transfection of plasmids into Saos-2 and U 20 S cells were done by calcium phosphate DNA precipitation and into Cos-7 cells by electroporation. For $\mathrm{N}$ orthern blot analysis, total cellular RNA was isolated by the $\mathrm{LiCl} /$ urea method, analyzed by electrophoresis by use of $0.8 \%$ agarose/formal dehyde gels, and transferred to Genescreen Plus (NEN), followed by hybridization by use of standard procedures. A 200-bp probe specific for the 3' untranslated sequence of hsp70.1 was derived by PCR amplification by use of primers (sense) GGGGCCTTTCCAAGATTGCTG and (antisense) CAACTTAAAAAATGGCCTGAGTTAAGT.

Preparative protein isolation and microsequencing analysis

Cellular lysates were extracted from $10^{9}$ U2OS cells with inducible expression of WT1-delZ, a carboxy-terminal truncation that does not inhibit cellular proliferation but retains the domain required for coprecipitation of the 65-kD band. Lysates 
were extracted with $50 \mathrm{~mm}$ Tris, at $\mathrm{pH} 8.0,400 \mathrm{~mm} \mathrm{NaCl}, 1 \%$ N P-40 and $1 \mathrm{~mm}$ EDTA, precleared by use of protein A Sepharose and incubated with rabbit polyclonal anti-WT 1 antibody WT 1c8, which had been covalently crosslinked to protein A Sepharose (Harlow and Lane 1988). Immunoprecipitated proteins were resolved by preparative gel el ectrophoresis and transferred to nitrocellulose. The coprecipitated $65-\mathrm{kD}$ band was visualized by staining with Ponceau, excised and subjected to protein microsequencing analysis (Harvard University Protein Microsequencing Facility).

\section{Antibodies and immunological methods}

The WTc8 rabbit polyclonal antibody, directed against the amino-terminal domain of WT 1 , has been described previously, and the carboxy-terminal monoclonal antibody was purchased from Santa Cruz. The goat polycl onal anti body K20 (Santa Cruz) was used to detect hsp70. For immunoprecipitation and for Western blot analyses, lysates were extracted by use of $50 \mathrm{~mm}$ Tris, at pH 8.0, $400 \mathrm{~mm} \mathrm{~N} \mathrm{aCl}, 1 \% \mathrm{NP}-40$ and $1 \mathrm{~mm}$ EDTA, and Western and immunoprecipitation analyses were performed according to standard protocol. For immunofluorescence analysis, cells were fixed with $4 \%$ paraformal dehyde, permeabilized with $1 \% \mathrm{~N}$ onidet P-40/10 mm glycine, preadsorbed with $3 \%$ bovine serum albumin (BSA), and exposed to either rabbit anti-WT1 antibody WTC8 or mouse anti-Hsp70 antibody W27, followed by either rhodamine-conjugated goat anti-rabbit antibody or fluorescein-conjugated goat anti-mouse antibody (Jackson ImmunoResearch). The mouse monoclonal antibody 12-CA-5 against the HA epitope was used to detect the tagged EWS-WT 1 chimeric product. Samples were analyzed by a laser confocal microscope (Bio-Rad M RC600 imaging system with Zeiss axiovert microscope) by use of $X 63$ and $X 100$ planeofluar objectives. For WT 1 immunohistochemical analysis, best results were obtained with frozen sections from 13-week human kidney that were fixed with acetone, hydrated with $10 \%$ goat serum in PBS, and incubated with the mouse monoclonal antibody mWT 12 $(10 \mu \mathrm{g} / \mathrm{ml})$, followed by the secondary goat anti-mouse antibody conjugated to horseradish peroxidase (Jackson ImmunoResearch). For Hsp70 immunohistochemistry, optimal results were obtained by use of formalin-fixed, paraffin-embedded sections of 13-week kidney. Sections were deparaffinized with xylene, hydrated with graded alcohol, microwaved for $10 \mathrm{~min}$ at $100^{\circ} \mathrm{C}$, blocked with $0.1 \mathrm{mg} / \mathrm{ml}$ avidin-D (Vector, Burlingame, $\mathrm{CA}$ ) containing $1 \%$ goat serum, and incubated with the mouse monoclonal anti-Hsp70 antibody W27, followed by biotin-labeled rabbit anti-mouse antibody, followed by avidin-biotinylated peroxidase complex (Vector) as described (Bhan 1995).

\section{CAT assays and FACS analysis}

To analyze transcriptional activation of the hsp70 promoter by WT1 variants, U2OS were transiently transfected with CMVdriven constructs, al ong with reporters encoding hsp70 regulatory sequences upstream of chloramphenicol acetyl transferase (CAT) (kindly provided by R. Kingston, MGH, Boston, MA). Experiments were undertaken in triplicate, and the amount of transfected CM V sequences was equal ized by addition of empty vector. Transfection efficiency was standardized by cotransfection of a human growth hormone reporter ( $\mathrm{N}$ ichols Institute), CAT activity was determined by use of standard procedures, and quantitated by scintillation counting, following chromatography on TLC plates. To analyze the transactivational properties of WT1 and DNAJ-WT1 variants with prototype WT1responsive promoters, CMV-driven expression constructs were cotransfected into U2OS cells either with the Early Growth
Response 1 reporter (EGR1-CAT), which contains the classical GC-rich WT1 binding sites, or with the reporter (EGFR-CAT), which has TC-rich sites that are also recognized by WT1. To measure the ability of WT1 and DNAJ-WT1 variants to inhibit cellular proliferation, U2OS and Saos-2 cells were transfected with CMV-driven constructs along with a hygromycin-resistance plasmid. Cultures were sel ected for growth in hygromycin for 2-3 weeks, stained, and drug-resistant colonies were counted. To anal yze the effect of WT1 and DNAJ-WT1 variants on cell cycle progression, Saos-2 cells in logarrhythmic growth phase were transiently transfected with these constructs, al ong with a plasmid encoding the cell surface marker CD20 as described by van den Heuvel and Harlow (1993). Cells were fixed $36 \mathrm{hr}$ after transfection and stained for CD20 expression and for DNA content by use of propidium iodide. The cell cycle distribution of CD20 positive cells was determined by FACS analysis. To determine the effect of WT1 andDNAJ-WT1 variants on expression of endogenous p21, cells were transiently transfected as above, and transfection efficiency was quantitated by use of a growth hormone reporter. Equal amounts of cellular lysates from cultures with comparable transfection efficiencies were anal yzed for p21 expression by Western blotting analysis, by use of antibody CP36 (kindly provided by E. Harlow). The high transfection efficiency of Saos-2 cells and the low baseline expression of p21 in these p53-null cells made it possible to detect induction of the endogenous p21 gene foll owing transient transfection of expression constructs.

\section{Acknowledgments}

We are grateful to R. Kingston for valuable advice and for providing hsp70 promoter constructs and to $\mathrm{R}$. Morimoto for the gift of antibodies to HSF1 and 2. We are also indebted to L. Ellisen and J. Settleman for critical ly reviewing this manuscript. This work was supported by $\mathrm{N}$ ational Institutes of $\mathrm{Heal}$ th grant CA 58596 (D.A.H.).

The publication costs of this article were defrayed in part by payment of page charges. This article must therefore be hereby marked "advertisement" in accordance with 18 USC section 1734 solely to indicate this fact.

\section{References}

Abravaya, K., M. Myers, S. Murphy, and R. Morimoto. 1992. The human heat shock protein hsp70 interacts with HSF, the transcription factor that regulates heat shock gene expression. Genes \& Dev. 6: 1153-1164.

A goff, S.N., J. Hou, D.I. Linzer, and B. Wu. 1993. Regulation of the human hsp70 promoter by p53. Science 259: 84-87.

Bhan, A.K. 1995. Immunoperoxidase. In Diagnostic immunopathology (ed. R.B. Colvin, A.K. Bhan, and R.T. McCluskey) 2nd edition, pp. 711-723, Raven Press, NY.

Bonnycastle, L.L., C.E. Yu, C.R. Hunt, B.J. Trask, K.P. Clancy, J.L. Weber, D. Patterson, and G.D. Schellenberg. 1994. Cloning, sequencing, and mapping of the human chromosome 14 heat shock protein gene (HSPA2). Genomics 23: 85-93.

Campbell, K., K. Mullane, I. Aksoy, H. Stubdal, J. Zalvide, J. Pipas, P. Silver, T. Roberts, B. Schaffhausen, and J. DeC aprio. 1997. Dnal/hsp40 chaperone domain of SV 40 large T antigen promotes efficient viral DNA replication. Genes \& Dev. 11: 1098-1110.

Cheetham, M.E., J.P. Brion, and B.H. Anderton. 1992. Human homologues of the bacterial heat-shock protein Dnal are preferntially expressed in neurons. Biochem. J. 284: 469476. 
Cotto, J., M. Kline, and R. M orimoto. 1996. Activation of heat shock factor 1 DNA binding precedes stress-induced serine phosphorylation. Evidence for a multistep pathway of reguIation. J. Biol. Chem. 271: 3355-3358.

Creighton, T. 1991. Unfolding protein folding. Nature 352: 1718.

Englert, C., X. Hou, S. M aheswaran, P. Bennett, C. N gwu, G. Re, A. Garvin, M. Rosner, and D. Haber. 1995a. WT 1 suppresses synthesis of the epidermal growth factor receptor and induces apoptosis. EMBO J. 14: 4662-4675.

Englert, C., M. Vidal, S. M aheswaran, Y. Ge, R. Ezzell, K. Isselbacher, and D. Haber. 1995b. Truncated WT1 mutants alter the subnuclear localization of the wild-type protein. Proc. Natl. Acad. Sci. 92: 11960-11964.

Englert, C., S. Maheswaran, A.J. Garvin, J. Kreidberg, and D.A. Haber. 1997. Induction of p21 by the Wilms' tumor suppressor gene WT1. Cancer Res. 57: 1429-1434.

Finlay, C., P. Hinds, T. Tan, D. Eliyahu, M. Oren, and A. Levine. 1988. Activating mutations for transformation by p53 produce a gene product that forms an hsc70-p53 complex with an altered half-life. Mol. Cell. Biol. 8: 531-539.

Garcia-Bermejo, L., N. Vilaboa, C. Perez, E. deBlas, C. Calle, and P. Aller. 1995. M odulation of hsp70 and hsp27 gene expression by the differentiation inducer sodium butyrate in U-937 human promonocytic leukemia cells. Leuk. Res. 19: 713718.

Haber, D. and D. Housman. 1992. The genetics of Wilms' tumor. Adv. Cancer Res. 59: 41-68.

Haber, D., A. Buckler, T. Glaser, K. Call, J. Pelletier, R. Sohn, E. Douglass, and D. Housman. 1990. An internal deletion within an 11p13 zinc finger gene contributes to the development of Wilms' tumor. Cell 61: 1257-1269.

Haber, D., R. Sohn, A. Buckler, J. Pelletier, K. Call, and D. Housman. 1991. Alternative splicing and genomic structure of the Wilms tumor gene WT1. Proc. Natl. Acad. Sci. 88: 96189622.

Haber, D., S. Park, S. M aheswaran, C. Englert, G. Re, D. HazenM artin, D. Sens, and A. Garvin. 1993. WT 1-mediated growth suppression of Wilms tumor cells expressing a WT 1 splicing variant. Science 262: 2057-2059.

Hainaut, P. and J. Milner. 1992. Interaction of heat-shock protein 70 with p53 translated in vitro: Evidence for interaction with dimeric p53 and for a role in the regulation of p53 conformation. EMBO J. 11: 3513-3520.

Harlow, E. and D. Lane. 1988. In Antibodies: A laboratory manual. Cold Spring Harbor Laboratory, Cold Spring Harbor, NY.

Hartl, F. 1996. M olecular chaperones in cellular protein folding. Nature 381: 571-580.

Hastie, N. 1994. The genetics of Wilms' tumor-a case of disrupted development. Annu. Rev. Genet. 28: 523-558.

Hightower, L.E. 1991. Heat shock, stress proteins, chaperones, and proteotoxicity. Cell 66: 191-197.

Huff, V., H. Miwa, D. Haber, K. Call, D. Housman, L. Strong, and G. Saunders. 1991. Evidence for WT 1 as a Wilms tumor (WT) gene: Intragenic germinal deletion in bilateral WT. Am. J. Hum. Genet. 48: 997-1003.

Hunt, C. and R. M orimoto. 1985. Conserved features of eukaryotic hsp70 genes reveal ed by comparison with the nucleotide sequence of human hsp70. Proc. Natl. Acad. Sci. 82: 64556459.

Johnson, J. and E. Craig. 1997. Protein folding in vivo: Unraveling complex pathways. Cell 90: 201-204.

Jones, K., J. Kadonaga, P. Rosenfeld, T. Kelly, and R. Tijan. 1987. A cellular DNA-binding protein that activates eukaryotic transcription and DN A replication. Cell 48: 79-89.
Kanei-Ishii, C., J. Tanikawa, A. Nakai, R. Morimoto, and S. Ishii. 1997. Activation of heat shock transcription factor 3 by c-myb in the absence of cellular stress. Science 277: 246248.

Kao, H.T. and J.R. N evins. 1983. Transcriptional activation and subsequent control of the human heat shock gene during adenovirus infection. Mol. Cell. Biol. 3: 2058-2065.

Kent, J., A.M. Coriat, P.T. Sharpe, N.D. Hastie, and V. van Heyningen. 1995. The evolution of WT1 sequence and expression pattern in the vertebrates. Oncogene 11: 17811792.

Khandjian, E.W. and H. Turler. 1983. Simian virus 40 and polyoma virus induce synthesis of heat shock proteins in permissive cells. Mol. Cell. Biol. 3: 1-8.

Khanna, A., R. Aten, and H. Behrman. 1995. Heat shock protein70 induction mediates luteal regression in the rat. Mol. Endocrinol. 9: 1431-1440.

Kingston, R.E., A.S. Baldwin, and P.A. Sharp. 1984. Regulation of heat shock protein 70 gene expression by c-myc. Nature 312: 280-282.

Koskinen, P.J., L. Sistonen, G. Evan, R. Morimoto, and K. Alitalo. 1991. N uclear colocalization of cellular and viral myc proteins with hsp70 inmyc-overexpressing cells. J. Virol. 65: 842-851.

Kreidberg, J., H. Sariola, J. Loring, M. Maeda, J. Pelletier, D. Housman, and R. Jaenisch. 1993. WT 1 is required for early kidney development. Cell 74: 679-691.

Kudoh, T., T. Ishidate, M. Moriyama, K. Toyoshima, and T. Akiyama. 1995. G1 phase arrest induced by Wilms' tumor protein WT 1 is abrogated by cyclin/CDK complexes. Proc. Natl. Acad. Sci. 92: 4517-4521.

Ladanyi, M. and W. Gerald. 1994. Fusion of the EWS and WT 1 genes in the desmoplastic small round cell tumor. Cancer Res. 54: 2837-2840.

Landel, C., P. Kushner, and G. Greene. 1994. The interaction of human estrogen receptor with DNA is modulated by receptor-associated proteins. Mol. Endocrinol. 8: 1407-1419.

Langer, T., C. Lu, H. Echols, J. Flanagan, M. Hayer, and F. Hartl. 1992. Successive action of DnaK, Dnal, and GroEL al ong the pathway of chaperone-mediated protein folding. Nature 356: 683-689.

Larsson, S., J. Charlieu, K. M iyagawa, D. Engelkamp, M. Rassoutzadegan, A. Ross, F. Cuzin, V. vanHeyningen, and N. Hastie. 1995. Subnuclear localization of WT 1 in splicing or transcription factor domains is regulated by alternative splicing. Cell 81: 391-401.

Leppa, S., L. Pirkkala, H. Saarento, K. Sarge, and L. Sistonen. 1997. Overexpression of HSF2-b inhibits hemin-induced heat shock gene expression and erythroid differentiation in K562 cells. J. Biol. Chem. 272: 15293-15298.

Liberek, K., D. Wall, and C. Georgopoulos. 1995. The Dnal chaperone catalytically activates the DnaK chaperone to preferentially bind the sigma 32 heat shock transcriptional regulator. Proc. Natl. Acad. Sci. 92: 6224-6228.

Lindquist, S. and E.A. Craig. 1988. The heat shock response. Annu. Rev. Genet. 22: 631-677.

Little, M., J. Prosser, A. Condie, P. Smith, V. van Heyningen, and N. Hastie. 1992. Zinc finger point mutations within the WT 1 gene in Wilms tumor patients. Proc. Natl. Acad. Sci. 89: 4791-4795.

Lum, L.S., S. Hsu, M. Vaewhongs, and B. Wu. 1992. The hsp70 gene CCAAT-binding factor mediates transcriptional activation by the adenovirus Ela protein. Mol. Cell. Biol. 12: 25992605.

Maheswaran, S., S. Park, A. Bernard, J. M orris, F. Rauscher III, D. Hill, and D. Haber. 1993. Physical and functional in- 
terction between WT1 and p53 proteins. Proc. Natl. Acad. Sci. 90: 5100-5104.

Maheswaran, S., C. Englert, P. Bennett, G. Heinrich, and D. Haber. 1995. The WT1 gene product stabilizes p53 and inhibits p53-mediated apoptosis. Genes \& Dev. 9: 2143-2156.

Milarski, K. and R. M orimoto. 1986. Expression of human hsp70 during the synthetic phase of the cell cycle. Proc. Natl. Acad. Sci. 83: 9517-9521.

Milner, C.M. and R.D. Campbell. 1990. Structure and expression of three MHC-linked HSP70 genes. Immunogenetics 32: 242-251.

Mitchell, P.J. and R. Tijan. 1989. Transcriptional regulation in mammalian cells by sequence-specific DNA binding proteins. Science 245: 371-378.

M osser, D., J. Duchaine, and B. M assie. 1993. The DN A-binding activity of the human heat shock transcription factor 1 is regulated in vivo by hsp70. Mol. Cell. Biol. 13: 5427-5438.

M undlos, S., J. Pelletier, A. Darveau, M. Bachmann, A. Winterpacht, and B. Zabel. 1993. N uclear localization of the protein encoded by the Wilms' tumor gene WT 1 in embryonic and adult tissues. Development 119: 1329-1341.

Pelletier, J., W. Bruening, C. KAshtan, S. Mauer, J. Manivel, J. Striegel, D. Houghton, C. Junien, R. Habib, L. Fouser, R. Fine, B. Silverman, D. Haber, and D. Housman. 1991a. Germline mutations in the Wilms' tumor suppressor gene are associated with abnormal urogenital development in DenysDrash syndrome. Cell 67: 437-447.

Pelletier, J., W. Bruening, F. Li, D. Haber, T. Glaser, and D. Housman. 1991b. WT1 mutations contribute to abnormal genital system development and hereditary Wilms' tumour. Nature 353: 431-434.

Pinhasi-Kimshi, O., D. Michal ovitz, A. Ben-Zeev, and M. Oren. 1986. Specific interaction between the p53 cellular tumour antigen and major heat shock proteins. Nature 320: 182-185.

Pritchard-Jones, K., S. Fleming, D. Davidson, W. Bickmore, D. Porteous, C. Gosden, J. Bard, A. Buckler, J. Pelletier, D. Housman, V. Heyningen, and N. Hastie. 1990. The candi date Wilms' tumour gene is involved in genitourinary development. Nature 346: 194-197.

Rabindran, S.K., G. Giorgi, J. Clos, and C. Wu. 1991. Molecular cloning and expression of a human heat shock factor, HSF1. Proc. Natl. Acad. Sci. 88: 6906-6910.

Rauscher III, F. 1993. The WT1 Wilms tumor gene product: A devel opmental ly regulated transcription factor in the kidney that functions as a tumor suppressor. FASEB J. 7: 896-903.

Rauscher III, F., J. M orris, O. Tournay, D. Cook, and T. Curran. 1990. Binding of the Wilms' tumor locus zinc finger protein to the EGR-1 consensus sequence. Science 250: 1259-1262.

Reddy, J. and J. Licht. 1996. The WT 1 Wilms tumor suppressor gene: How much do we really know? Biochim. Biophys. Acta 1287: 1-28.

Reddy, J., S. Hosono, and J. Licht. 1995. The transcriptional effect of WT 1 is modulated by choice of expression vector. J. Biol Chem. 270: 29976-29982.

Sarge, K.D., V. Zimarino, K. Holm, C. Wu, and R.I. Morimoto. 1991. Cloning and characterization of two mouse heat shock factors with distinct inducible and constitutive DNA-binding ability. Genes \& Dev. 5: 1902-1922.

Schlesinger, M. 1991. Heat shock proteins. J. Biol. Chem. 265: 12111-12114.

Schowalter, D., W. Sullivan, N. Maihle, A. Dobson, O. Connely, B. O'M alley, and D. Toft. 1991. Characterization of progesterone receptor binding to the 90 and $70 \mathrm{kDa}$ heat shock proteins. J. Biol. Chem. 166: 21165-21173.

Schuetz, T., G. Gallo, L. Sheldon, P. Tempst, and R. Kingston. 1991. Isolation of a cDNA for HSF2: Evidence for two heat shock factor genes in humans. Proc. Natl. Acad. Sci. 88: 6911-6915.

Silver, P. and J. Way. 1993. Eukaryotic Dnal homologs and the specificity of hsp70 activity. Cell 74: 5-6.

Sistonen, L., K. Sarge, B. Phillips, K. Abravaya, and R. Morimoto. 1992. Activation of heat shock factor 2 during hemininduced differentiation of human erythroleukemia cells. Mol. Cell. Biol. 12: 4104-4111.

Smith, D. and D. Toft. 1993. Steroid receptors and their associated proteins. Mol. Endocrinol. 7: 4-11.

Sorger, P. 1991. Heat shock factor and the heat shock response. Cell 65: 363-366.

Stubdal, H., J. Zalvide, K. Campbell, C. Schweitzer, T. Roberts, and J. DeCaprio. 1997. Inactivation of pRB-related proteins p130 and p107 mediated by the J domain of simian virus 40 large T antigen. Mol. Cell. Biol. 17: 4979-4990.

Teshima, S., K. Rokutan, M. Takahashi, T. Nikawa, and K. Kishi. 1996. Induction of heat shock proteins and their possible roles in macrophages during activation by macrophage colony-stimulating factor. Biochem. J. 315: 497-504.

Tsai, J. and M. Douglas. 1996. A conserved HPD sequence of the J-domain is necessary for YDJ1 stimulation of hsp70 ATPase activity at a site distinct from substrate binding. J. Biol. Chem. 271: 9347-9354.

Varanasi, R., N. Bardeesy, M. Gharemani, M.-J. Petruzzi, N. Nowak, M. Adam, P. Grundy, T. Shows, and J. Pelletier. 1994. Fine structure analysis of the WT1 gene in sporadic Wilms tumors. Proc. Natl. Acad. Sci. 91: 3554-3558.

van den Heuvel, S. and E. Harlow. 1993 Distinct roles for cyclindependent kinases in cell cycle control. Science 262: 20502054.

Wall, D., M. Zylick, and C. Georgopoulos. 1994. The NH2terminal 108 amino acids of the Escherichia coli DnaJ protein stimulate the ATPase activity of DnaK and are sufficient for I replication. J. Biol. Chem. 269: 5446-5451.

Wang, Z., Q. Qiu, K. Enger, and T. Deuel. 1993. A second transcriptionally active DN A-binding site for the Wilms tumor gene product, WT1. Proc. Natl. Acad. Sci. 90: 88968900.

Wu, B.J. and R.I. M orimoto. 1985. Transcription of the human hsp70 gene is induced by serum stimulation. Proc. Natl. Acad. Sci. 82: 6070-6074.

Wu, B., C. Hunt, and R. M orimoto. 1985. Structure and expression of the human gene encoding major heat shock protein hsp70. Mol. Cell. Biol. 5: 330-341.

Wu, B.J., H.C. Hurst, N.C. Jones, and R.I. Morimoto. 1986. The E1A 135 product of adenovirus 5 activates transcription of the cellular human hsp70 gene. Mol. Cell. Biol. 6: 29942999.

Wu, C. 1995. Heat shock transcription factors: Structure and regulation. Annu. Rev. Cell. Dev. Biol. 11: 441-469. 


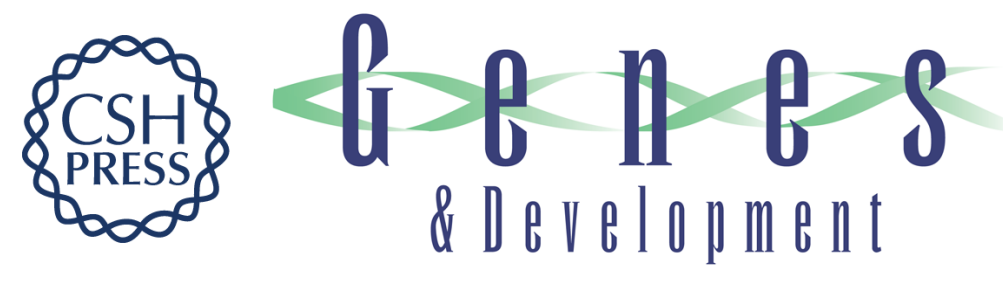

\section{Inhibition of cellular proliferation by the Wilms tumor suppressor WT1 requires association with the inducible chaperone Hsp70}

Shyamala Maheswaran, Christoph Englert, Gang Zheng, et al.

Genes Dev. 1998, 12:

References This article cites 75 articles, 42 of which can be accessed free at:

http://genesdev.cshlp.org/content/12/8/1108.full.html\#ref-list-1

License

Email Alerting

Receive free email alerts when new articles cite this article - sign up in the box at the top

Service

right corner of the article or click here.

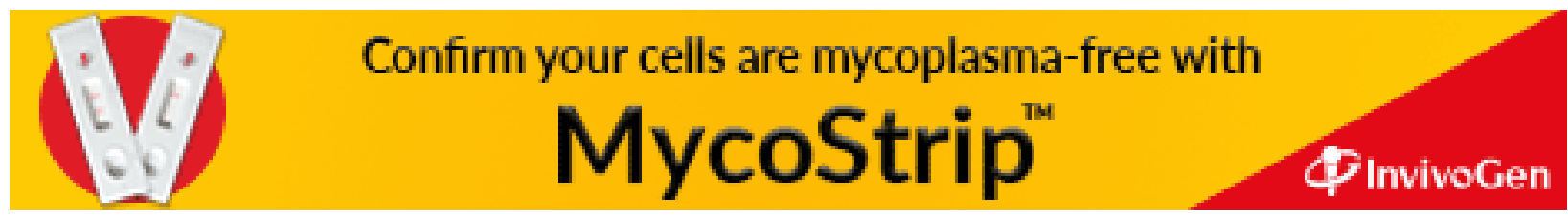

